UDC $81-11$

DOI: $10.17223 / 24109266 / 7 / 4$

\title{
THE METHODOLOGICAL VALUE OF THE CONCEPT "TEXT" FOR THE ANALYSIS OF THE COMMUNICATIVE SPACE OF THE CITY
}

\author{
S.V. Pirogov, V.V. Kashpur \\ Tomsk State University (Tomsk, Russia). \\ E-mail: pirogoff@ngs.ru; valkashpur@inbox.ru
}

\begin{abstract}
City is always a palimpsest: a heterogeneous continuum consisting of numerous realities. The innovativeness of urban environment, the generation of new text appears in the endless interpretation of the semiotics of the city by different actors of the communicative space. The "frozen text" of the city turns into intertext that can be analyzed using the principles of "textual analysis" of Roland Barthes. Perception and interpretation of the semiotics of the city is in the form of cognitive models which are personal and social schemas that appear depending on the situation in the course of development and appropriation of the semiotics of urban environment by subjects of the city's communicative space. Cognitive models as products of discursive practices are generating structures of new topoi of the space of the city.
\end{abstract}

Keywords: Urban text; communicative space of city; palimpsest; intertext; discursive practices; cognitive model of environment.

\section{Introduction}

In the history of humanitarian thought there is a structuralist and poststructuralist understanding of the text. The structuralist understanding of the text of the city comes from the thesis that the products of the activity of previous generations exist as the symbolic aspect of the city, as the cultural and historical layer of ancestors' life in a symbolic form. Here we speak about the toponymy, landscape marks, architectural signs, and the mental image of the city as a whole as a representation of a certain picture of the world. The city looks like a stable semiotic system, as a trans-personal and transsubjective reality that determines the typical perception of the city. But every place is not only perceived, but also interpreted and re-interpreted. The text is not only read, but also re-read and understood in a different way. Poststructuralism is not concerned with the "frozen text", the semiotic structure; it concentrates on textual activity which is the process of forming and changing the perceptions of reality.

The purpose of this paper is to analyze the communicative space of the city as a mechanism of generating new meanings. We analyze sociosemantic situations, i.e. variants of how the subjects of perception interpret urban environment as a whole and its individual fragments. 


\section{Methods of Research}

In post-structuralism each text is an intertext: the text always includes a lot of other texts. The city is always a palimpsest: urban environment is a heterogeneous continuum consisting of multiple overlapping realities. "Multitude is achieved by addressing different aspects of the place itself, by analyzing the source texts of various levels of the hierarchy, as well as by the plurality of authors" [1: 178]. The innovativeness of urban environment, the generation of new text appear in the endless interpretation of the city semiotics (assessment, description, analysis, etc.) by different actors of the communicative space. According to Barthes, intertextual (innovative and semantic) multitude is focused on a certain point which is not the author but the reader [2]; in our case it is the subjects of urban dialogues (including dialogues with the architectonics of urban environment). The concept "dialogue" is used to express the procedural aspect of communication.

"Forms of dialogue are absolutely infinite. Any demonstrative characteristics, objects, all forms of self-manifestation of the human are read as text and become an element of urban dialogue. Such diverse phenomena as forms of economic life, market, conflict, any interaction are dialogue in the space of the city. Politics, courtship, love games, art, architecture, journalism, science, urban folklore: all these and many more are forms of dialogue. The number of subjects of such a dialogue is almost incalculable: the collective and the individual, and the city as a whole" [3: 95].

\section{Results of Research}

In the communicative space of the city there is a transition "from works to text" [2]. The primary text is isomorphic to a thing, a specific situation, a practical context of interaction in traditional society and is a product, a symbolic analogue of reality. Creating intertextuality is playing with signs. "The difference here is this: the product is a material fragment... while Text is a methodological field ("un champ méthodologique")" [Ibid]. Barthes" principles of "textual analysis" as an analysis of the communicative mechanism of conceptualization can be used to study human behavior in urban environment. Such communicative mechanisms, according to Barthes, are: "code of communication", the principle of "curvature", the principle of "irreversibility" [Ibid].

"The codes are simply associative fields... which impose a certain idea of structure. Codes are certain types of deja-vu, of already seen, already read, already made" [Ibid]. The code is a system of meanings that constitutes a certain image of the city and the corresponding behavior practices in urban environment. In dialogue the communicative code determines the communicative intention, i.e. the mental focus on a fragment of reality in order to de- 
velop the understanding of the situation in the communication (dialogue) mode. Similar communicative intentions of the subjects of the city's communicative space create a possibility of a common representation of social reality and, in the future, of projects and models of joint activities.

Barthes' principle of "curvature" is associated with the so-called "floating microstructure of the text". Both perception and interpretation of space are due to some prior personal knowledge. The post-structuralist approach to text interpretation is based on cognitive psychology and cognitive linguistics. The image of a place is a cognitive model that contains the memory of the place, the previous experience and intention. Cognitive models store knowledge (memory) of episodes of personal attitude to the fragments of environment and experience of situations, rather than a simple statement of some events and things. In the case of cognitive models we do not deal with reality as such, but with a personally and socially constructed reality schema.

"Yet the difference with an actual representation of a particular discourse (the text-base) is that the model schema may take much information in its terminal categories that is not and need not be expressed in sentences or discourse, e.g., because it is presupposed general knowledge or personal episodic memories that are not relevant in a particular discourse" [4: 174175]. This information is not within formal linguistic structures, but it is this information that sets the context of what is happening, and, if it is relevant to a different subject of communication, it promotes a uniform interpretation of the situation.

Personal knowledge is a collection of objects as personally significant fragments of reality. Personal knowledge is formed as practical knowledge in the process of personal development of the surrounding reality. In the interaction with other actors of urban communication, intersubjective knowledge (a social (group) definition of the situation) appears as social cognition or a cognitive model of the environment in a social situation. Social cognition is a schematization of social knowledge of the world; it is a social text allowing individuals to orient in it and build cooperative behavior models as ways to respond to changing situations. The definition of the situation is based on intention, a focus of attention and activity on a meaningful subject, rather than on the status.

The intentional component of the cognitive model of a place is formed as the interference of personal motives and common interests. The system of interests exists as a project, the analogue of which in the text is intention. Personal meaning and the schema of joint operational actions, interacting with each other in the practice of social behavior, create a new text and a new practice. Fluctuations of meanings in urban environment create new schemas of perception and behavior that are generating structures of social behavior and interaction. Dridze notes that research of substantial processes 
in communication systems like "city" requires the development of intentional analysis of urban community texts as semio-socio-psychological groups [5].

The content of the text, by Barthes, is always connected with the "horizon of expectations" of the reader. In the social context, the "horizon of expectations" is formed as the interference of social situation requirements and personal intentions. New texts as new semantic (symbolic) situations appear at three communicative levels: semiotic (the content proper of a sign); sociolinguistic (the content of a sign in a socio-linguistic community); personal (the individual psychological and situational interpretation of a sign).

The principle of "irreversibility" of the semantics of urban environment draws attention to the fact that reading the old text in a new situation creates a new text. The communicative space of the city is a space of discursive practices, symbolic "tactics" of behavior in a semiotic space. Michel de Certeau, who studied the city from the perspective of semiotic analysis, states that the communicative space of the city is a space of symbolic "tactics" of behavior which are different ways of development and appropriation of the objectively existing, current and historical environment in the unity of its object and subject structure. Cultural and historical layers of the city semiotics store certain "strategies" of their creators, personal development and appropriation of the semiotics of urban environment: "tactics" generate "space stories". "Thus, we can compare signifying practices... to space creating ones" [6: 48].

Semantic objects of the city in discursive practices are woven into the life and biography of city dwellers as personally developed and biographically memorable. They become personally significant places, part of the personality: personal life loci. Taken at the level of urban communities as groups with homogenous motivational intentions (semio-socio-psychological groups), significant loci of personal life integrate into the system of urban life topoi (stable elements of the communicative space of the city). Thus, the space of the city is formed as the interference of semiotics (meanings and senses) and topology (developed and habitus environment), which John Lo noted [7].

In turn, the cognitive model of the city, i.e. the form of its mental representation, becomes a generating structure. It specifies the form of perception and vision, and, thus, ways to "operate" it. Therefore, perceptually we can live in alternative worlds, using various "sets" or various canons of representation for different contexts. A perceptual alternative enables a practical alternative, new modes of vision generate new projects.

Discourse is produced not only by speech acts but also by non-verbal means of communication: drama of the social game, symbolic use of the physical parameters of the environment. Non-verbal aspects of the communication space of the city are: proxemic (the use of the object sphere) and kinesthetic (territorial morphology and corresponding bodily behaviors). 


\section{Conclusion}

The concept "text" is a tool for analyzing the semiotic mechanism of the innovative communicative space of the city. The new in urban environment is a result of spontaneous, unexpected, unplanned encounter and subsequent interaction of diverse semiotic elements. The chaos of objects and meanings of urban environment is the direct synergistic mechanism for the development of the city. The semiotic chaos of city life is a generator of randomness and diversity that make up a new unity, that form new semantic and socio-relational structures.

\section{References}

1. Mitin, I.I. (2004) Mifogeografiya: novye podkhody k osmysleniyu kul'tury i prostranstva [Myth geography: new approaches to understanding the culture and space]. Antropologicheskie konfiguratsii sovremennoy filosofii: Materialy nauch. konf. [Anthropological configuration of modern philosophy: Conference Proc.] Moscow: Sovremennye tetradi. p. $178-180$.

2. Barthes, R. (1994) Izbrannye raboty: Semiotika. Poetika [Selected Works: Semiotics. Poetics]. Moscow: Progress; Univers. p. 384-391.

3. Yakovenko, I.G. (1999) Gorod v prostranstve dialoga kul'tur i dialog goroda [City in the dialogue of cultures and dialogue of the city]. In: Sayko, E.V. (ed.) Sotsiokul'turnoe prostranstvo dialoga [Socio-cultural space of dialogue]. Moscow: Nauka. p. 90-100.

4. Dijk, T. A. van. (1989) Yazyk. Poznanie. Kommunikatsiya [Language. Cognition. Communication] Moscow: Progress. p. 68-110.

5. Dridze, T.M. (1999) Sotsiokul'turnaya kommunikatsiya: tekst i dialog v semiosotsiopsikhologii [Socio-cultural communication: text and dialogue in semio-sociopsychology]. In: Sayko, E.V. (ed.) Sotsiokul'turnoe prostranstvo dialoga [Socio-cultural space of dialogue]. Moscow: Nauka. p. 58-77.

6. Certeau, M. de. (2005) Po gorodu peshkom [Walking round the city]. Communitas. Soobshchestvo. 2. p. 80-87.

7. Lo, J. (2006) Ob'ekty i prostranstva [Objects and spaces]. Sotsiologicheskoe obozrenie. 5 (1). p. 41-42.

Information about the authors:

Pirogov Sergey V., Associate Professor, Department of Sociology, Faculty of Philosophy, Tomsk State University (Tomsk, Russia). E-mail: pirogoff@ngs.ru

Kashpur Valeria V., Assistant Professor, Romance-Germanic Philology Department, Faculty of Philology, Tomsk State University (Tomsk, Russia).E-mail: valkashpur@inbox.ru 